\title{
Characterization and Taxonomic Description of Five Mycoplasma Serovars (Serotypes) of Avian Origin and Their Elevation to Species Rank and Further Evaluation of the Taxonomic Status of Mycoplasma synoviae
}

\author{
F. T. W. JORDAN ${ }^{1}$, H. ERN $\emptyset,{ }^{2}$ G. S. COTTEW,${ }^{3}$ K. H. HINZ, ${ }^{4}$ AND L. STIPKOVITS ${ }^{5}$ \\ Avian Medicine, Liverpool University Veterinary Field Station, "Leahurst," Neston, Merseyside, United \\ Kingdom ${ }^{1}$; Food and Agriculture Organization/World Health Organization Collaborating Centre for Animal \\ Mycoplasmas, Institute of Medical Microbiology, University of Aarhus, DK 8000, Aarhus C, Denmark ${ }^{2}$; \\ Commonwealth Scientific and Industrial Research Organisation, Division of Animal Health, Animal Health \\ Research Laboratory, P. O. Parkville, Victoria, Australia $3052^{3}$; Institut fur Geflugelkrankheiten, Der \\ Tierarztlichen Hochschule Hannover. 3 Hannover, Bischofsholer Damm 15, West Germany ${ }^{4}$; and Veterinary \\ Medical Research Institute, Hungarian Academy of Sciences, Budapest XIV, Hungaria Korut 21, Hungary ${ }^{5}$
}

Characterization of the reference strains of avian mycoplasma serovars (serotypes) C, D, F, I, and L, namely CKK (= ATCC $33553=$ NCTC 10187), DD (= ATCC $33550=$ NCTC 10183), WR1 $(=$ ATCC $33551=$ NCTC 10186 $), 695(=$ ATCC $33552=$ NCTC 10185), and $694(=$ ATCC $33549=$ NCTC 10184), respectively, indicates that the serovars are distinct species, and the following names have been suggested for them: $M$. pullorum, $M$. gallinaceum, $M$. gallopavonis, $M$. iowae, and $M$. columbinasale, respectively. The above-mentioned reference strains are designated as the type strains of their respective species. Further biochemical and serological examination of the properties of Mycoplasma synoviae also confirm this to be a separate species.

Mycoplasma serovars (serotypes) C, D, F, and $\mathrm{I}$, isolated from chickens or turkeys, and serovar $\mathrm{L}$ from pigeons, have been considered for a number of years to belong to separate species. However, characterization of these serovars in terms of the minimum requirements proposed by the Subcommittee on the Taxonomy of Mycoplasmatales of the International Committee on Systematic Bacteriology (1971) (22) and the Subcommittee on the Taxonomy of Mollicutes (1979) (21) has not hitherto been undertaken. Members of the Board of the Food and Agriculture Organization (FAO)/World Health Organization Program on Comparative Mycoplasmology (now known as the International Organization for Mycoplasmology Research Program on Comparative Mycoplasmology) selected one reference strain for each of these serovars, and members of the avian team of the program examined these strains on the basis of the proposals of the 1972 committee. Additional examinations included the determination of the deoxyribonucleic acid (DNA) base composition and immunofluorescence examinations of the cross-reactions obtained by growth inhibition (GI) tests. Mycoplasma synoviae (14), originally isolated from the hock joint of a chicken (15), was included since comprehensive serological comparison with other avian and mammalian isolates had not been made. A number of the characteristics of some of the serovars have already been published outside of the team studies, but reference is made to the published results of authors only when the strains used and the methods employed are in keeping with the standards indicated by the above-mentioned subcommittees.

The composition of the team participating in these studies has changed over the period of study, but some members have made a contribution throughout and constitute the authors of this article. Other members are indicated in the Acknowledgments.

\section{MATERIALS AND METHODS}

Mycoplasma strains and specific antisera. The following Mycoplasma strains were used: mammalian strains Mycoplasma agalactiae PG2, $M$. alkalescens $\mathrm{D} 12, M$. alvi Ilsley, $M$. arginini $\mathrm{G} 230, M$. arthritidis PG6, $M$. bovigenitalium PG11, $M$. bovirhinis PG43, $M$. bovis Donetta, $M$. bovoculi M165/69, M. buccale $\mathrm{CH} 20247, M$. canadense $257 \mathrm{C}, M$. canis $\mathrm{PG} 14, M$. capricolum California Kid, $M$. caviae $\mathrm{G} 122, M$. citelli BG2C, $M$. conjunctivae HRC581, $M$. cynos H831, $M$. dispar 462/2, $M$. edwardii $\mathrm{PG} 24, M$. equigenitalium T37, $M$. equirhinis M432/72, $M$. faucium DC333, $M$. feliminutum BEN, $M$. felis CO, $M$. fermentans PG18, $M$. flocculare Ms42, M. gateae CS, M. hominis PG21, $M$. hyopneumoniae $\mathrm{J}, M$. hyorhinis BTS-7, $M$. hyosynoviae S16, M. lipophilum MaBy, M. maculosum 
PG15, M. moatsii MK405, M. molare H542, M. mycoides subsp. capri PG3, M. mycoides subsp. mycoides PG1, $M$. neurolyticum A, $M$. opalescens MH5408, M. orale CH19299, M. ovipneumoniae Y-98. $M$. pneumoniae $\mathrm{FH}, M$. primatum HRC292, M. pulmonis PG34, $M$. putrefaciens $\mathrm{KS}-1, M$. salivarium PG20, $M$. spumans PG13, $M$. sualvi Mayfield B, $M$. subdolum TB, and $M$ verecundum 107 and avian strains $M$. anatis $1340, M$. gallinarum PG16, $M$. gallisepticum PG31, $M$. iners PG30, $M$. meleagridis 17529, Acholeplasma laidlawii PG8, and A. laidlawii PG9. All of the Mycoplasmatales strains and specific antisera used in this study were obtained from the FAO/World Health Organization Collaborating Center for Animal Mycoplasmas, Aarhus, Denmark, except the antiserum for $M$. sualvi, which was kindly supplied by J. G. Tully, Mycoplasma Section, National Institutes of Health, Bethesda, Md.

The six strains subjected to characterization tests and used by all participants in this study were serovar C, reference strain CKK (= ATCC $33553=$ NCTC 10187), isolated by Fabricant from the trachea of a chicken (12); serovar D, reference strain DD (= ATCC $33550=$ NCTC 10183), isolated by Fabricant from the trachea of a chicken (12); serovar F, reference strain WR1 ( = ATCC 33551 = NCTC 10186), isolated by Roberts from air-sac lesions in adult turkeys (17); serovar I, reference strain $695(=$ ATCC $33552=$ NCTC 10185), isolated by Yoder and Hofstad from airsac lesions of pipped turkey embryos (25); serovar L, reference strain $694(=$ ATCC $33549=$ NCTC 10184), isolated by Yoder and Hofstad from pigeon turbinates (26); and $M$. synoviae, reference strain WVU 1853 , isolated by Olson et al. from the hock joint of a chicken (15) and named by Olson et al. (14).

All of the above-mentioned strains were filter cloned by each participant by conventional procedures (22) with 450-nm filters.

All observations and tests were performed by at least two team members working with their own clones of the above-mentioned strains but using standard procedures $(21,22)$.

Media. The media used for the characterization tests are as described below with their respective methods. For general cultural procedures, team members used one of the following media or a medium of similar composition.

Broth medium consisted of a mycoplasma broth base $(1.5 \%, \mathrm{wt} / \mathrm{vol})$, inactivated horse or swine serum (15 to $20 \%, \mathrm{vol} / \mathrm{vol})$, yeast extract $(10 \%, \mathrm{vol} / \mathrm{vol})$, glucose or arginine $(1 \%, \mathrm{wt} / \mathrm{vol})$, thallium acetate $(0.05 \%$, wt/vol), and $1,000 \mathrm{U}$ of penicillin per $\mathrm{ml}$; for $M$. synoviae, this was supplemented with $0.01 \%$ (wt/ vol) nicotinamide adenine dinucleotide. For solid medium, $1 \%$ agar was added.

Morphology. Organisms from fluid cultures ( 2 to 3 days old) were studied by light microscopy after being fixed in methanol and stained with Giemsa solution; unfixed organisms were examined by dark-field microscopy.

For direct examination with the electron microscope (Phillips E.M. 300; accelerating voltage, $80 \mathrm{kV}$ ), a deposit was prepared from broth culture by centrifugation, washed three times in physiological saline fixed in $6.25 \%$ glutaraldehyde and then $2.0 \%$ osmic acid, dehydrated, transferred to epoxy propane, and embedded in araldite. Sections 50 to $60 \mathrm{~nm}$ thick were cut.
Colony morphology was observed with a stereoscopic microscope.

Filtration studies. The filterability of the strains was determined by using two different membrane filters with an average pore diameter of 450 and $220 \mathrm{~nm}$, respectively.

Reversion studies. The organisms were passaged five consecutive times with mycoplasma broth and agar without penicillin and thallium acetate and incubated aerobically at $37^{\circ} \mathrm{C}$. For the final culture, blood agar plates were also inoculated and incubated aerobically. After Dienes staining, colonies of the final culture on mycoplasma agar were examined macroscopically; the final broth culture was examined by dark-field microscopy.

Sterol requirement for growth. The method used to determine the sterol requirement of each strain was based on the method of Edward (7), and the basal medium recommended by him was used. To this was added bovine serum albumin $(0.5 \%, \mathrm{wt} / \mathrm{vol})$ and palmitic acid $(10 \mu \mathrm{g} / \mathrm{ml})$ plus either the PPLO serum fraction $(1 \%, \mathrm{vol} / \mathrm{vol})$ or varying amounts of cholesterol (from 0.2 to $100 \mu \mathrm{g} / \mathrm{ml}$ ). In addition, medium was prepared containing the basal medium with $15 \%$ swine serum.

The plates were incubated after inoculation with washed suspensions of culture which gave growth on control plates inoculated concurrently.

Inhibition of growth by digitonin was examined by the disk method of Freundt et al. (10); 6-mm-diameter filter paper disks, each soaked in $0.025 \mathrm{ml}$ of a $1.5 \%$ (wt/vol) solution of digitonin, were used.

Biochemical tests. The abilities of the strains to utilize glucose, arginine, and urea were investigated, using a basal medium composed of heart infusion broth $(74 \mathrm{ml})$, horse serum $(10 \mathrm{ml})$, yeast extract $(5$ $\mathrm{ml})$, benzyl penicillin $(1,000 \mathrm{U} / \mathrm{ml})$, thallium acetate $(0.05 \%, \mathrm{wt} / \mathrm{vol})$, and phenol red $(0.5 \%, \mathrm{wt} / \mathrm{vol})(1 \mathrm{ml})$. To this was added one of the following substrates to give a final concentration of $1 \%(\mathrm{wt} / \mathrm{vol}$ ): glucose (for which the $\mathrm{pH}$ of the medium was adjusted to 7.6), arginine, or urea (for each of which the $\mathrm{pH}$ was adjusted to 7.0 ).

Samples of these three different media in 2-ml amounts were inoculated with $0.1 \mathrm{ml}$ of a culture of the test mycoplasma in substrate-free broth and were incubated aerobically, except in the glucose tests, in which both aerobic and anaerobic conditions were used. The controls consisted of the substrate-free basal medium (volume adjusted with distilled water) inoculated with the test organism as well as the three uninoculated substrate-containing media. Also, for glucose and arginine, an appropriate control organism was inoculated into the corresponding medium with the substrate. Mycoplasma gallisepticum strain PG31 was the control organism for the glucose medium, and Mycoplasma gallinarum strain PG16 was the control organism for the arginine medium; no control was used for the urea medium.

During incubation, a fall in $\mathrm{pH}$ of 0.5 unit or more in glucose broth or a rise of 0.5 unit or more in arginine or urea broth, relative to the controls, was considered to indicate the utilization of the substrate. Incubation was continued for 21 days, and the tests were read at intervals of a few days.

Phosphatase activity and tetrazolium reduction were determined by the method of Aluotto et al. (1), 
and "film and spots" production was investigated by the method of Fabricant and Freundt (9).

DNA base composition. For strains CKK, DD, 695, WR1, and 694, DNA was extracted, and the guanine plus cytosine $(\mathrm{G}+\mathrm{C})$ content was determined by equilibrium density gradient centrifugation in $\mathrm{CsCl}$, using a Spinco model $\mathrm{E}$ analytical ultracentrifuge. The buoyant density was determined, using Escherichia coli DNA as an internal standard, and the $\mathrm{G}+\mathrm{C}$ content was calculated from the buoyant density by the equation of Schildkraut et al. (19).

For M. synoviae WVU 1853 , the $\mathrm{G}+\mathrm{C}$ content of the DNA was found by Kelton and Mandel (13) to be $34.2 \mathrm{~mol} \%$.

Serological studies. Serological tests included (i) GI, as described by the Working Group of the World Health Organization/FAO Program on Comparative Mycoplasmology (24), with some members using disks and others using wells ( 3 ) for the antiserum (inhibition zones of $1 \mathrm{~mm}$ or less were ignored); (ii) metabolism inhibition (MI) tests by the method of Taylor-Robinson et al. (23) for glucose-fermenting strains and by the method of Purcell et al. (16) for arginine-positive strains; (iii) indirect immunofluorescence (IF), as de scribed by Rosendal and Black (18) (one team member used the method of Bradbury et al. [4]); and (iv) immunodiffusion.

\section{RESULTS}

Cultural and morphological characteristics. All of the strain except $M$. synoviae WVU 1853 grew on the standard media within 2 to 3 days at $37^{\circ} \mathrm{C}$ both aerobically and with increased carbon dioxide; WVU 1853 required nicotinamide adenine dinucleotide for growth.

Colonies of all of the strains exhibited the typical "fried-egg" appearance on solid media, but colonies without the central papilla were also seen.

The organisms were gram-negative, and upon Giemsa staining, all strains appeared mainly coccobacillary in form. Dark-field microscopy confirmed a predominance of coccoid elements with some pleomorphism.

Examination of thin sections with the electron-microscope confirmed the pleomorphism and showed that cells of all of the strains were bounded by a triple-layered unit membrane and lacked a cell wall (Fig. 1).

On the external part of the cell membrane of the CKK and 695 strains there seemed to be an unusual amount of attached material. This is reminiscent of the observations made on the Mycoplasma dispar and Mycoplasma meleagridis strains.

Filtration studies. The results of the filtration studies are given in Table 1.

Reversion studies. There was no colonial or cultural evidence of reversion to cell-walled bacterial forms when the strains were grown in media from which inhibitors had been omitted. Also, no morphological evidence of reversion was seen in cultures by light-microscope examination of smears or dark-field examination of broth cultures.

Sterol requirements. A washed suspension of cells of each of the strains produced no growth on basal sterol-free agar but produced growth similar to that produced on the standard medium when swine serum $(15 \%$, wt/vol) was added. The same kind of inoculum failed to grow on the sterol-free agar plus bovine serum albumin and palmitic acid alone or when supplemented with $0.2 \mu \mathrm{g}$ of cholesterol per $\mathrm{ml}$. However, when this medium was supplemented with 5 to $100 \mu \mathrm{g}$ of cholesterol per ml, growth was obtained with each of the strains.

In disk inhibition tests, growth of all of the strains was inhibited by digitonin, with the inhibitory zones being at least $4 \mathrm{~mm}$ wide.

Biochemical characteristics. Biochemical characteristics of the six reference strains are given in Table 2.

DNA base composition. The average $G+C$ contents of the DNAs obtained from two separate, independent estimations were as follows: strain CKK, 29 mol\%; strain DD, 28 mol\%; strain WR1, 27 mol\%; strain 695, 25 mol\%; strain 694, 32 mol\%; and strain WVU 1853, 34 mol\% (13).

Serological studies. The main serological method by which the six strains under consideration were tested against the strains listed above was the GI test. This was a two-way test, and it was supplemented by the MI, IF, and immunodiffusion tests against a more restricted range of mycoplasmas. Each of the 6 strains under consideration was compared serologically in at least one test with 57 other Mollicutes strains as well as with each other, and each was compared more extensively, as shown below, with the other known avian strains.

GI tests. Complete growth inhibition of the six strains tested was produced by their homologous antisera (Table 3). Growth inhibition of strain 694 by antiserum to strain WVU 1853 was demonstrated by one of three team members

TABLE 1. Results of filtration studies on the six Mycoplasma reference strains

\begin{tabular}{lccc}
\hline \multirow{2}{*}{ Strain } & \multicolumn{3}{c}{ Viable counts per $0.1 \mathrm{ml}$} \\
\cline { 2 - 4 } & Unfiltered & \multicolumn{2}{c}{ Filtered } \\
\cline { 3 - 4 } & & $450 \mathrm{~nm}^{a}$ & \multicolumn{1}{c}{$220 \mathrm{~nm}^{a}$} \\
\hline CKK & $2.3 \times 10^{8}$ & $2.0 \times 10^{6}$ & No recovery \\
DD & $1.6 \times 10^{7}$ & $3.5 \times 10^{6}$ & No recovery \\
WR1 & $6.1 \times 10^{7}$ & $1.7 \times 10^{6}$ & No recovery \\
695 & $1.6 \times 10^{8}$ & $4.2 \times 10^{7}$ & $5.1 \times 10^{2}$ \\
694 & $1.4 \times 10^{6}$ & $1.7 \times 10^{4}$ & No recovery \\
WVU 1853 & $4.7 \times 10^{6}$ & $1.5 \times 10^{6}$ & $4.4 \times 10^{3}$ \\
\hline
\end{tabular}

a Pore diameter of filters. 

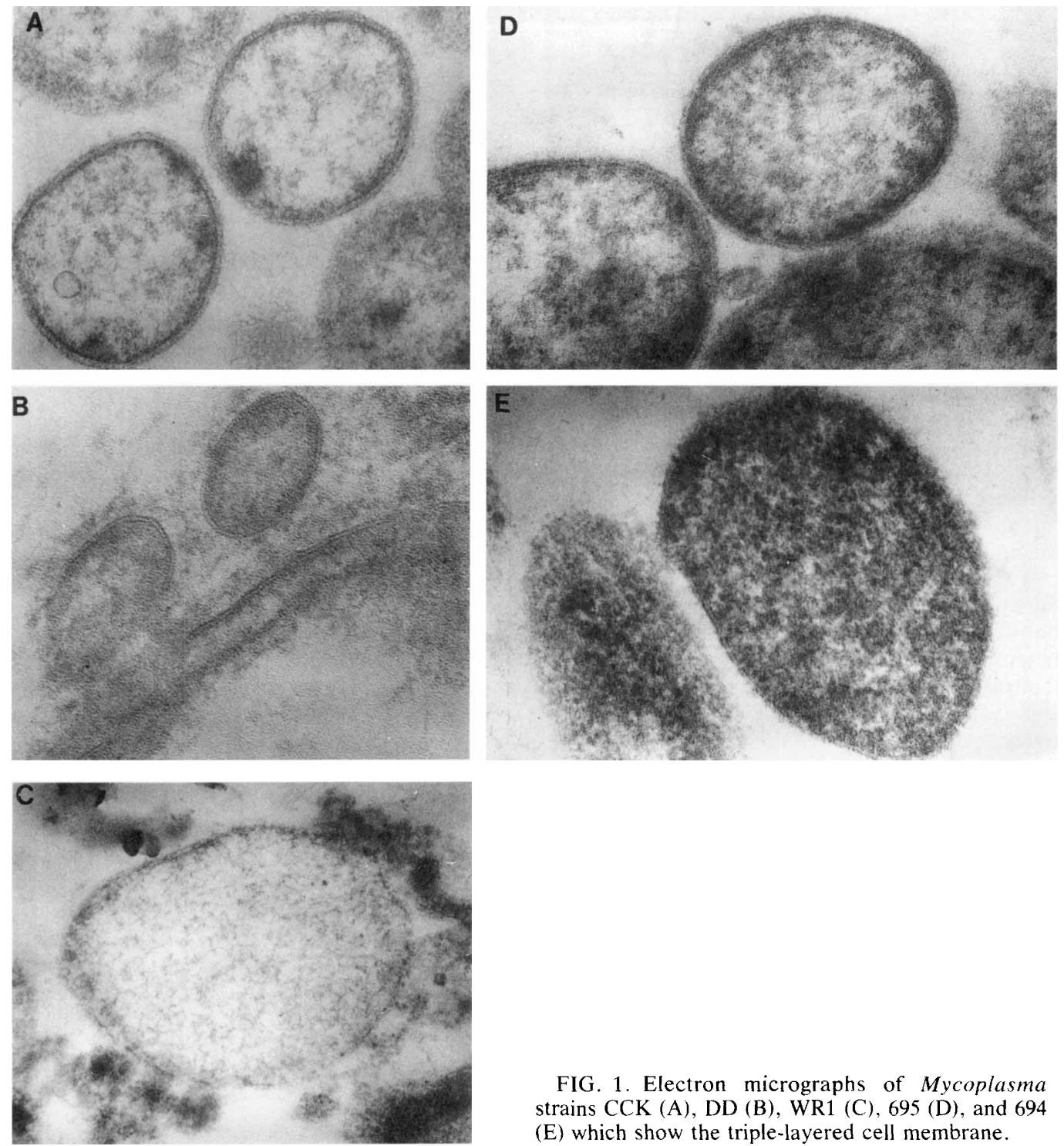

FIG. 1. Electron micrographs of Mycoplasma strains CCK (A), DD (B), WR1 (C), 695 (D), and 694 (E) which show the triple-layered cell membrane.

performing this test, but the zones of inhibition were much smaller than those of the homologous reaction, and reciprocal tests showed it to be a one-way cross-inhibition. Similarly, growth inhibition of strain WVU 1853 was produced by antiserum for $M$. orale strain CH 19299.

Heterologous growth inhibition of four strains was observed by some team members with antisera to the six strains being examined (Table 4). The zones of inhibition varied from 1.5 to 3.0 $\mathrm{mm}$, were not complete in any of the reactions, and were always less than those in the corresponding homologous tests; reciprocal inhibition was not produced.

MI tests. The six strains under examination

were each tested against antisera for the avian species and serovars (Table 5) and reciprocally.

The homologous titers obtained by the team members varied, but in each case they were considerably higher than the heterologous titers. Heterologous reactions of low titer were observed with antisera to strains CKK, WR1, 694, and WVU 1853, and reciprocal metabolic inhibition was only seen between strains WR1 and WVU 1853, again at low titers.

IF tests. The avian strains listed in Table 5 and their antisera were tested homologously and reciprocally by $\mathrm{IF}$. Bright fluorescence was obtained with homologous reactants, but negative results were obtained in all of the heterologous 
TABLE 2. Biochemical characteristics of the six Mycoplasma reference strains

\begin{tabular}{|c|c|c|c|c|c|c|}
\hline \multirow{2}{*}{ Strain } & \multicolumn{3}{|c|}{ Utilization of: } & \multirow{2}{*}{$\begin{array}{l}\text { Reduction of } \\
\text { tetrazolium } \\
\text { chloride }\end{array}$} & \multirow{2}{*}{$\begin{array}{c}\text { Phosphatase } \\
\text { activity }\end{array}$} & \multirow{2}{*}{$\begin{array}{l}\text { Film and } \\
\text { spots }\end{array}$} \\
\hline & Glucose $\mathrm{e}^{a}$ & Arginine & Urea & & & \\
\hline CKK & + & - & - & - & - & - \\
\hline DD & + & - & - & - & - & - \\
\hline WR1 & + & - & - & - & - & - \\
\hline 695 & + & + & - & $++^{b}$ & - & - \\
\hline 694 & - & + & - & - & + & + \\
\hline WVU 1853 & + & - & - & - & - & + \\
\hline
\end{tabular}

${ }^{a}$ The strains metabolizing glucose produced a color change within 3 days of either aerobic or anaerobic incubation at $37^{\circ} \mathrm{C}$.

${ }^{b}$ The color change was more intense under anaerobic conditions

tests. Two-way IF tests were also undertaken on the strains involved in cross-reactions in the GI tests (Tables 3 and 4), with negative results.

Immunodiffusion tests. The results of two-way immunodiffusion tests for all of the avian strains, including the six under examination, are shown in Table 6. Cross-reactions occurred with all of the strains, and for many they were reciprocal, but the number of precipitin lines obtained with heterologous reactants was always fewer than that obtained with homologous reactants.

The results of the reactions between antisera to the mammalian strains listed above and the strains under examination are shown in Table 7. Cross-reactions occurred against all of the strains except against strain 695, for which there were none. Cross-reactions were limited to a few mammalian strains, except with strain 694, against which 13 strains produced precipitins. Cross-reactions in every case were associated with fewer precipitin lines than the number obtained in homologous reactions among the six strains under examination.

\section{DISCUSSION}

Our results confirm the earlier observations of others in the following respects: strain 694 pro-

TABLE 3. Results of GI tests on six Mycoplasma reference strains

\begin{tabular}{ll}
\hline \multicolumn{1}{c}{ Antigen } & \multicolumn{1}{c}{ Antisera causing growth inhibition } \\
\hline CKK & Homologous only $(3.5-6)^{a}$ \\
DD & Homologous only $(2-3.5)^{a}$ \\
WR1 & Homologous only $(5-8)^{a}$ \\
695 & Homologous only $(2.5-9)^{a}$ \\
694 & Homologous $(4-10)^{a} ;$ WVU $1853(1.3)^{a}$ \\
& (by 1 of 3 team members) \\
WVU 1853 & Homologous $(2.5-8)^{a} ; M$. orale \\
& CH19299 $(2)^{a}($ by 1 of 5 team \\
& members, where the homologous \\
& inhibition zone was 5 mm)
\end{tabular}

${ }^{a}$ Figures within parentheses indicate complete inhibition in millimeters with minima and maxima obtained by team members. duced film and spots and reduced tetrazolium (2), failed to ferment glucose (6), and had a $\mathrm{G}+\mathrm{C}$ value of 32.1 mol\% (13); strain 695 failed to produce film and spots but reduced tetrazolium aerobically (2), fermented glucose (6), and had a $\mathrm{G}+\mathrm{C}$ value of $24.5 \mathrm{~mol} \%$ (13); strain WVU 1853 required nicotinamide adenine dinucleotide for growth (5).

The following features shown by strains CKK, DD, 695, WR1, 694, and WVU 1853 indicate that the strains belong to the class Mollicutes: typical fried-egg morphology of at least some colonies of all of the strains under examination; the passage of cells through 450$\mathrm{nm}$ filters and the passage of some cells through 220-nm filters; pleomorphism of cell form, as seen by dark-field illumination, although Giemsa staining showed mainly coccobacillary forms; the absence of a cell wall but the presence of a triple-layered membrane, as indicated by thinsection electron microscopy; and the failure of organisms to revert to bacterial forms on noninhibitory substrates. In this connection, however, it should be pointed out that the strains examined had probably been subcultured on

TABLE 4. Heterologous reactions of antisera of strains CKK, DD, WR1, 695, 694, and WVU 1853 against the strains listed in the text

\begin{tabular}{ll}
\hline Antiserum & \multicolumn{1}{c}{ Heterologous GI } \\
\hline CKK & $\begin{array}{l}\text { Mycoplasma mycoides subsp. } \\
\text { mycoides PG1 (2-3) }\end{array}$ \\
& M. neurolyticum A (2) \\
& M. agalactiae PG2, $(1.5)^{a}$ \\
& M. capricolum California Kid, $(1.5)^{a}$ \\
DD & M. neurolyticum A (2) \\
WR1 & M. neurolyticum A (3) \\
WVU 1853 & M. neurolyticum A (3) \\
695 & M. neurolyticum A (3) \\
694 & M. neurolyticum A (3) \\
& M. mycoides subsp. mycoides PG1 (2)
\end{tabular}

${ }^{a}$ Figures within parentheses indicate partial inhibition in millimeters obtained by one of three or four team members. 
TABLE 5. Results of MI tests between strains of recognized avian species and strains CKK, DD, WR1, 695, 694, and Mycoplasma synoviae WVU 1853

\begin{tabular}{|c|c|c|}
\hline \multirow[b]{2}{*}{ Rabbit antiserum to: } & \multicolumn{2}{|c|}{ Titer against: } \\
\hline & $\begin{array}{c}\text { Homologous } \\
\text { organism“ }\end{array}$ & Heterologous organism \\
\hline Mycoplasma gallisepticum PG31 & $2,560->10,240$ & 0 \\
\hline M. gallinarum PG16 & $5,120->20,480$ & 0 \\
\hline CKK & $320-5,120$ & $\mathrm{DD}(<80)$ \\
\hline DD & $320-5,120$ & 0 \\
\hline M. iners PG30 & $1,280->20,480$ & 0 \\
\hline WR1 & $320->20,480$ & $\begin{array}{l}695(<80) ; \text { WVU } 1853(<80) ; M \\
\text { anatis } 1340(80) ; \text { PG8 }(160) ; \\
\text { PG9 }(160)\end{array}$ \\
\hline M. meleagridis 17529 & $1,280->20,480$ & 0 \\
\hline 695 & $640-5.120$ & 0 \\
\hline 694 & $320-10,240$ & PG8 $(<80)$ \\
\hline M. synoviae WVU 1853 & $640-10,240$ & PG16 (80); DD (80); WR1 $(<80)$ \\
\hline M. anatis 1340 & $640-10,240$ & 0 \\
\hline Acholeplasma laidlawii PG8 & $1,280-2,560$ & PG9 (160) \\
\hline A. laidlawii PG9 & $1,280-2,560$ & PG8 (80) \\
\hline
\end{tabular}

${ }^{a}$ Minimum and maximum titers obtained by team members are shown.

numerous occasions before testing for reversion to bacterial forms. The low DNA base ratios of the strains $(\mathrm{G}+\mathrm{C}$ content, 25 to $32 \mathrm{~mol} \%)$ are also in keeping with the majority of species of the class Mollicutes.

The failure of all of the strains to grow in sterol-free medium, their inhibition by digitonin, and their morphology meet the requirements for inclusion in the family Mycoplasmataceae.

Furthermore, the ability of these strains to grow aerobically and their inability to utilize urea place them in the genus Mycoplasma.

The results of the serological studies de- scribed above show that strains CKK, DD WR1, 695, and $M$. synoviae WVU 1853 are distinct from the type strains of all previously named Mycoplasma species, including those of avian origin, except $M$. columborale and $M$. columbinum, which differ at least from strains 695, 694, and M. synoviae WVU 1853 (20).

The cross-reactions which were noted in the GI test (Tables 3 and 4) were one-way only, showed partial inhibition with a number of "break-through" colonies, and showed zones which were in every case significantly smaller than those of the homologous reactions. Fur-

TABLE 6. Results of immunodiffusion tests between strains of the recognized avian species and strains CKK, DD, WR1, 695, 694, and Mycoplasma synoviae WVU 1853

\begin{tabular}{|c|c|c|}
\hline \multirow[b]{2}{*}{ Rabbit antisera to: } & \multirow[b]{2}{*}{$\begin{array}{l}\text { Homologous } \\
\text { organism }\end{array}$} & Number of precipitin lines produced against: \\
\hline & & Heterologous organism \\
\hline Mycoplasma gallisepticum PG31 & $4-5$ & CKK (1) \\
\hline M. gallinarum $\mathrm{PG} 16$ & $4-5$ & M. iners PG30 (2); M. meleagridis $17529(2) ; 694(1)$ \\
\hline CKK & $4-5$ & DD $(1-2) ; 695(0-1) ; 694(0-1)$ \\
\hline DD & $3-4$ & $\begin{array}{l}\text { WR1 (1); M. meleagridis } 17529(2) ; 695(0-1) ; 694(1) \text {; WVU } \\
\quad 1853(0-1) ; M . \text { anatis } 1340(1-2)\end{array}$ \\
\hline$M$. iners $\mathrm{PG} 30$ & $4-5$ & $\begin{array}{l}\text { M. gallisepticum PG31 (2); } M \text {. gallinarum PG16 (2); } \\
\text { M. meleagridis } 17529(1-2) ; 694(1)\end{array}$ \\
\hline WR1 & 4 & M. anatis $1340(2)$ \\
\hline M. meleagridis 17529 & $3-4$ & $\begin{array}{l}\text { M. gallinarum PG16 (2); CKK (2); DD (1); } \\
\text { M. iners PG30 (1) }\end{array}$ \\
\hline 695 & $4-5$ & DD $(0-1) ; 694(1)$ \\
\hline 694 & $4-6$ & $\begin{array}{l}\text { M. gallinarum PG } 16(1-2) ; \text { CKK (1); DD }(0-1) ; M \text {. iners } \\
\text { PG30 (2); WR1 }(0-1) ; M \text {. meleagridis } 17529(1) ; 695(1-2)\end{array}$ \\
\hline M. synoviae WVU 1853 & $2-3$ & M. gallisepticum PG31 (1); CKK (2); WR1 (1); 694 (1) \\
\hline$M$. anatis 1340 & $4-5$ & DD $(0-1) ; 695(1)$ \\
\hline Acholeplasma laidlawii PG8 & $3-6$ & 695 (1); Acholeplasma laidlawii PG9 (2-5) \\
\hline A. laidlawii PG9 & $2-5$ & 695 (1); A. laidlaw'ii PG8 (1-3) \\
\hline
\end{tabular}


TABLE 7. Results of immunodiffusion tests between antisera for the mammalian species and strains listed in the text and strains CKK, DD, WR1, 695, 694, and WVU 1853

\begin{tabular}{|c|c|}
\hline Avian strain & Mycoplasma strains (no. of precipitin lines produced with heterologous sera) \\
\hline$\overline{\mathrm{CKK}}$ and DD & M. cynos $\mathrm{H} 31(2) ;$ M. felis CO (2); M. edwardii PG24 (2) \\
\hline WR1 & M. cynos $\mathrm{H} 31$ (2); M. felis $\mathrm{CO}(2) ; M$. edwardii PG24 (2); $M$. pneumoniae FH (1) \\
\hline 694 & 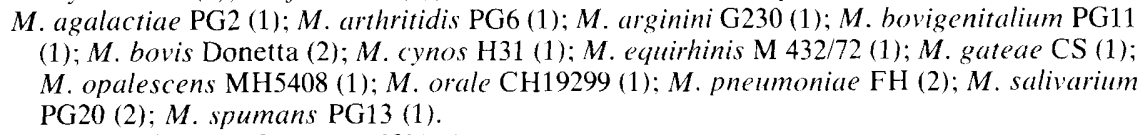 \\
\hline WVU 1853 & M. canis PG14 (1); M. cynos $\mathrm{H} 31$ (1) \\
\hline
\end{tabular}

thermore, IF gave homologous reactions only.

The MI tests for the avian strains showed that the homologous titers were always considerably higher than the heterologous titers and, in most cases, occurred only in one-way cross-reactions. Exceptions to this were strains WR1 and WVU 1853; with these strains, two-way crossreactions occurred, but at titers much lower than those of the homologous reactions.

The immunodiffusion tests were limited to the avian strains in two-way tests and to the sera only of all of the other strains. Whereas a number of heterologous reactions occurred, the number of precipitin lines were always lower with heterologous reactants.

It may be concluded from these serological tests that the six strains under examination each belong to separate species.

Further distinguishing features of these six isolates are the distinct values for the $\mathrm{G}+\mathrm{C}$ contents of the DNAs, the specific electrophoretic patterns of the amino acid components compared with all other avian strains (11), and certain biochemical reactions.

Since the strains studied represented all of the relevant Mycoplasma species presently required to be tested for taxonomic purposes (21), it is concluded that strains CKK, DD, WR1, 695, and 694 are members of new and distinct species and that $M$. synoviae is confirmed as a unique species. The following names are proposed for the five previously unnamed taxa represented by the following organisms. CKK: Mycoplasma pullorum (L. n. pullus a young animal, especially chicken; L. n. gen. pullorum of chickens); DD: Mycoplasma gallinaceum (L. n. gallus a domestic fowl; L. adj. gallinaceum pertaining to a domestic fowl); WR1: Mycoplasma gallopavonis (L. n. gallopavo a turkey; L. n. gen. gallopavonis of a turkey); 695: Mycoplasma iowae (among avian mycoplasmologists, the epithet "iowa" has been used for a number of years; the genitive form iowae [of iowa] is suggested); 694: Mycoplasma columbinasale (L. n. columbus a pigeon; L. n. gen. columbi of a pigeon; $\mathrm{L}$. adj. nasale pertaining to the nose; $\mathrm{L}$. adj. columbinasale pertaining to the nose of a pigeon).
Formal descriptions of the proposed new species and of Mycoplasma synoviae WVU 1853 follow.

The fact that these organisms are members of the class Mollicutes, family Mycoplasmataceae, and genus Mycoplasma was shown in the preceeding discussion, and characteristics of the individual species and of their respective type strains are given below.

Mycoplasma pullorum ferments glucose aerobically and anaerobically, does not utilize arginine or urea, and does not reduce tetrazolium chloride, show phosphatase activity, or produce film and spots. $\mathrm{G}+\mathrm{C}$ content of DNA: $29 \mathrm{~mol} \%$. Serologically distinct. Type strain: CKK (= ATCC $33553=$ NCTC 10187).

Mycoplasma gallinaceum ferments glucose aerobically and anaerobically, does not utilize arginine or urea, and does not ferment tetrazolium chloride, show phosphatase activity, or produce film and spots. $\mathrm{G}+\mathrm{C}$ content of DNA: 28 mol\%. Serologically distinct. Type strain: DD $(=$ ATCC $33550=$ NCTC 10183$)$.

Mycoplasma gallopavonis ferments glucose aerobically and anaerobically, does not utilize arginine or urea, and does not ferment tetrazolium chloride, show phosphatase activity, or produce film and spots. G+C content of DNA: 27 mol\%. Serologically distinct. Type strain: WR1 $(=$ ATCC $33551=$ NCTC 10186).

Mycoplasma iowae ferments glucose aerobically and anaerobically, utilizes arginine, does not utilize urea, ferments tetrazolium chloride aerobically and anaerobically, and does not show phosphatase activity or produce film and spots. $\mathrm{G}+\mathrm{C}$ content of DNA: 25 mol\%. Serologically distinct. Type strain: 695 (= ATCC 33552 = NCTC 10185)

Mycoplasma columbinasale does not ferment glucose, utilizes arginine, does not utilize urea or ferment tetrazolium chloride, shows phosphatase activity, and produces film and spots. $\mathrm{G}+\mathrm{C}$ content of DNA: 32 mol\%. Serologically distinct. Type strain: 694 (= ATCC $33549=$ NCTC 10184)

Mycoplasma synoviae ferments glucose aerobically and anaerobically, does not utilize arginine or urea, does not ferment tetrazolium chlo- 
ride or show phosphatase activity, and produces film and spots. $\mathrm{G}+\mathrm{C}$ content of DNA: $34 \mathrm{~mol} \%$. Serologically distinct. Type strain: WVU 1853 $(=$ ATCC $25204=$ NCTC 10124).

\section{ACKNOWLEDGMENTS}

We wish to acknowledge the help afforded us in some of the tests by the late D. G. ff. Edward, London, England: H. Gerlach, Oberschleissheim, Federal Republic of Germany; E. Goren, Doorn, The Netherlands; M. M. Z. Sabry, Cairo, Egypt; and J. G. Tully, Bethesda, Md. The DNA base compositions for strains CKK, DD, WR1, 695, and 694 were determined by M. S. Daniels (John Innes Institute, Norwich United Kingdom) on mycoplasma cultures provided by one of us (F.T.W.J.).

\section{REPRINT REQUESTS}

Reprints are not available.

\section{LITERATURE CITED}

1. Aluotto, B. B., E. G. Wittler, C. O. Williams, and J. E. Faber. 1970. Standardized bacteriologic techniques for the characterization of mycoplasma species. Int. J. Syst Bacteriol. 20:35-58.

2. Barber, T. L., and J. Fabricant. 1971. Identification of Mycoplasmatales: characterization procedures. Appl. Microbiol. 21:600-605.

3. Black, F. T. 1973. Modification of the growth inhibition test and its application to human T-mycoplasmas. Appl. Microbiol. 25:528-533.

4. Bradbury, J. M., C. Oriel, and F. T. W. Jordan. 1976. Simple method for immunofluorescent identification of mycoplasma colonies. J. Clin. Microbiol. 3:449-452.

5. Chalquest, R. R., and J. Fabricant. 1960. Pleuropneumonia-like organisms associated with synovitis in fowl. Avian Dis. 4:515-539.

6. Dierks, R. E., J. A. Newman, and B. S. Pomeroy. 1967 Characterization of avian mycoplasma. Ann. N.Y. Acad Sci. 143:170-189.

7. Edward, D. G. ff. 1971. Determination of sterol requirement for Mycoplasmatales. J. Gen. Microbiol. 69:205210.

8. Fabricant, J. 1969. Avian mycoplasmas, p. 621-641. In L. Hayflick (ed.), The Mycoplasmatales and the L-phase of bacteria. North Holland Publishing Co., Amsterdam.

9. Fabricant, J., and E. A. Freundt. 1967. Importance of extension and standardization of laboratory tests for the identification and classification of Mycoplasma. Ann. N.Y. Acad. Sci. 143:50-58

10. Freundt, E. A., B. E. Andrews, H. Ernф, M. Kunze, and F. T. Black. 1973. The sensitivity of Mycoplasmatales to sodium-polyethanol-sulphonate and digitonin. Zentralbl Bakteriol. Parasitenkd. Infektionskr. Hyg. Abt. 1 Orig. Reihe A 225:104-112.

11. Hinz, K. H., and U. Newmann. 1978. Vergleichende un- tersuchungen aviarer Mycoplasmen mittels FlachgelPolyacrylamid-Elektrophorese. Zentralbl. Bakteriol. Parasitenkd. Infektionskr. Hyg. Abt. 1 Orig. Reihe A 240:265-270

12. Jordan, F. T. W. 1979 . The mycoplasmas, p. 1-48. In J. G. Tully and R. T. Whitcomb (ed.), Avian mycoplasmas, vol. II. Academic Press, Inc., New York.

13. Kelton, W. H., and M. Mandel. 1969. Deoxyribonucleic acid base composition of mycoplasma strains of avian origin. J. Gen. Microbiol. 56:131-135.

14. Olson, N. O., H. E. Adler, A. J. DaMassa, and R. E. Corstvet. 1964. The effect of intranasal exposure to $M$. synoviae and infectious bronchitis on development of lesions and agglutinins. Avian Dis. 8:623-631.

15. Olson, N. O., D. C. Shelton, and D. A. Munro. 1957. Infectious synovitis control by medication. Effect of strain differences and pleuro-pneumonia-like organisms. Am. J. Vet. Res. 18:735-739.

16. Purcell, R. H., D. Taylor-Robinson, D. C. Wong, and R. M. Chanock. 1966. A colour test for the measurement of antibody to the non-acid-forming human mycoplasma species. J. Epidemiol. 84:51-66.

17. Roberts, D. H. 1963. The isolation of a previously unreported mycoplasma serotype and some observations on the incidence of mycoplasma in poultry. Vet. Rec. 75:665-667.

18. Rosendal, S., and F. T. Black. 1972. Direct and indirect immunofluorescence of unfixed and fixed mycoplasma colonies. Acta Pathol. Microbiol. Scand. Sect. B. 80:615622.

19. Schildkraut, C. L., J. Marmur, and P. Doty. 1962. Determination of the base composition of deoxyribonucleic acid from its buoyant density in CsCl. J. Mol. Biol. 4:430443.

20. Shimizu, T., H. Ernф, and H. Nagatomo. 1979. Isolation and characterization of Mycoplasma columbinum and Mycoplasma columborale. Two new species from pigeons. Int. J. Syst. Bacteriol. 28:538-546.

21. Subcommittee on the Taxonomy of Mollicutes. 1979. Proposals for minimal standards for descriptions of new species of Mollicutes. Int. J. Syst. Bacteriol. 29:172-180.

22. Subcommittee on the Taxonomy of Mycoplasmatales. 1972 Proposals for minimal standards for descriptions of new species of the order Mycoplasmatales. Int. J. Syst. Bacteriol. 22:184-188.

23. Taylor-Robinson, D., R. H. Purcell, D. C. Wong, and R. M. Chanock. 1966. A colour test for the measurement of antibody to certain mycoplasma species based upon the inhibition of acid production. J. Hyg. 64:91-104.

24. Working group of the WHO/FAO Programme on Comparative Mycoplasmology. 1976. The Growth Inhibition Test. World Health Organisation VPH/M/C/76.7.

25. Yoder, H. W., Jr., and M. S. Hofstad, 1962. A previously unreported serotype of avian mycoplasma. Avian Dis. 6:147-160.

26. Yoder, H. W., Jr., and M. S. Hofstad. 1964. Characterization of avian mycoplasma. Avian Dis. 8:481-512. 